\title{
Study of fracture features in foam bearing glass epoxy composites subjected to repeated impacts
}

\author{
S VENKATRAMAN and KISHORE* \\ Centre for Advanced Study, Department of Metallurgy, Indian Institute of Science. Bangalore \\ 560012, India \\ MS received 10 May 1996; revised 19 August 1996

\begin{abstract}
The paper reports the failure features observed in low mass repeatedly (pendulum) impacted glass epoxy composites with and without the mid section having either 2-layers or 3 -layers of flexible foam. Features such as through width and inclined cracks as well as adhering of foam observed in the experiments are explained. The significance of the foam material in modifying the impact response of the composite is stressed.
\end{abstract}

Keywords. Flexible foam; glass epoxy; impact; fractography.

\section{Introduction}

Fractographic features of conventional metallic materials are well catalogued and interpretations of fracture features fairly well systematised (Subramanian and Kishore 1986; ASM 1987; Murthy et al 1987). The same is not true for polymeric materials in general and polymer based composites in particular (Purslow 1986; Padmanabhan and Kishore 1990, 1994; Samajdar and Kishore 1991; Saratchandra et al 1991). Hence, the need to look into this aspect in advanced systems, which forms the subject matter of study for the present work, where macrographs are used to characterize the failure features in a widely used composite system, viz. E-glass epoxy compatible fibres and epoxy matrix.

The failure is not achieved in a single step operation, instead it is realized through repeated low mass pendulum (tup) impacts. This way the spread of the zone of damage as well as the response of the test material towards such repeated impacts, when flexible foam layers are inserted into the mid section of the laminate, can be studied.

By keeping the total thickness of the foam layers constant, whether a variation in the number of foam layers introduced in the mid section affects the failure pattern is also investigated and reported in this work. The report also briefly attempts to highlight the extent of spread of the interface delamination process by the use of colour dye penetrant.

\section{Materials and methods}

The plain and the foam bearing laminates were fabricated by hand lay up process. For the plain glass epoxy laminate, E-glass epoxy compatible woven fabric was laid over a well ground steel plate coated with a release coating/film. On every glass fabric layer a room temperature curing epoxy resin (made by Hindustan Ciba Geigy) mix was spread. A surface mat layer encompasses the lay up sequence (Kaushal and Kishore 1992). Spacers were used for getting the required thicknesses. The uncured material was

*For correspondence 
then pressed in a press and allowed to completely cure, at ambient temperature for $24 \mathrm{~h}$ and excess resin was squeezed out.

Fabrication of foam containing laminates also had a similar procedure except mid way through the lay up sequence either 3 layers of $6 \mathrm{~mm}$ thickness relatively small cell-sized or 2 layers of $9 \mathrm{~mm}$ thickness larger cell-sized foam were inserted. Both the foams were made of highly flexible and commercially available material. Between the foam layers and as well as on the top and bottom of the layers commercially available adhesive was smeared.

The plain and the foamed laminates had about similar final thicknesses. Burn out tests were carried out to assess among others the level of reinforcement achieved. These revealed the fibre content in the plain laminates to be around $50 \%$ by weight.

For impact testing, specimens were cut using a diamond tipped cutter for a good surface finish. The impact machine used for the experiments is a Hounsfield Plastics impact tester [No. P 224] of an earlier make. Rectangular test pieces of non standard dimensions, $5 \mathrm{~cm}$ long and $10 \mathrm{~mm}$ wide, were cut and used. The impact machine had a graduated scale on which a pointer moves after the failure of the sample to indicate the absorbed energy. Range of loads used was from $1 / 4 \mathrm{lb}$ to $2 \mathrm{lb}$. The foam free and foam bearing laminates were impacted first with either a $1 / 4$ or $1 / 2 \mathrm{lb}$ load, for a fixed number of hits and then allowed to fail by impacting with a higher load viz. $2 \mathrm{lb}$.

At variance to the above procedure a few select samples were made into a geometry having a square cross section (unlike the majority having width much larger than thickness used in the present experiments) and subsequently subjected to impacts on the face of the lay up (unlike the edge having the tup contact during impact for the other studies). This procedure was evolved first to see the response of the effect of geometry and second the orientation of the lay up vis-a-vis the impact direction on the failure sequence. Further in this experiment to monitor the progress due to the spread of the damaged region a colour dye penetrant was used.

Light macroscopy was carried out using a Neophot Microscope to bring out the failure features in test coupons with and without the foam material.

\section{Results and discussion}

Figure 1 illustrates the fracture occurring in the plain laminates as viewed from the width side. The through fracture (facilitated both by fibre fracture and matrix cracking) has a brightened zone immediately adjacent to the split face as is clearly visible in the photomacrograph. Figure 2 is another illustration of the through fracture occurring with a step like displacement. The slight decohesion in the form of a faint line leading to the split of the laminate, on the top side of the left portion of the sample is also visible. The split along the impact direction, whether straight or zig zag, depends on local stress situation, soundness of the composite, etc.

Figure 3 depicts many features seen in the impacted samples such as the delamination process, the mid plane separation and the zig zag appearance on the split face of the test coupon. It must be stressed, for the experimental conditions used in this work, the delamination (visible in this sample) is less frequently noticed in samples of this kind. A few samples had a through fracture but inclined to the specimen axis and this is depicted in figure 4 . Here, neither occasionally seen mid plane delamination nor very 


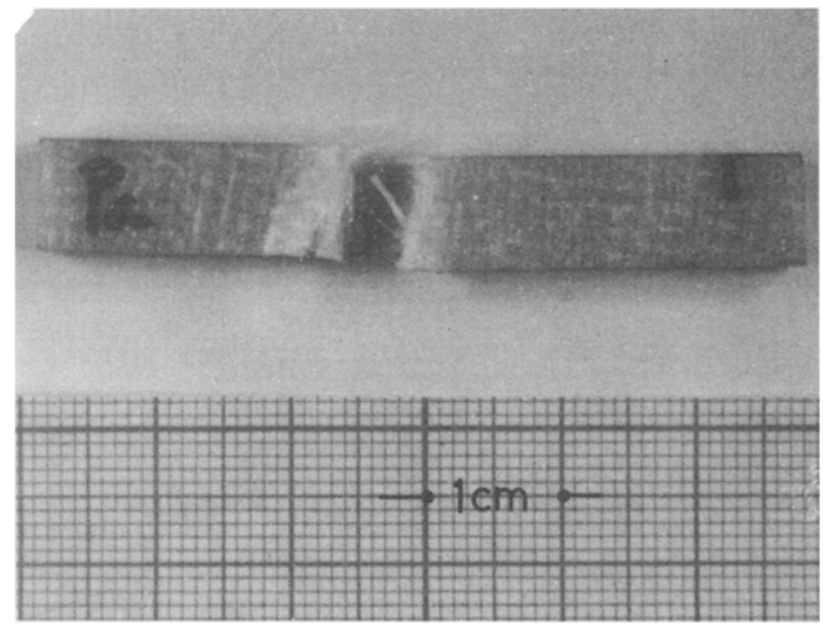

Figure 1. Macrograph showing the through fracture in a plain glass-epoxy laminate.

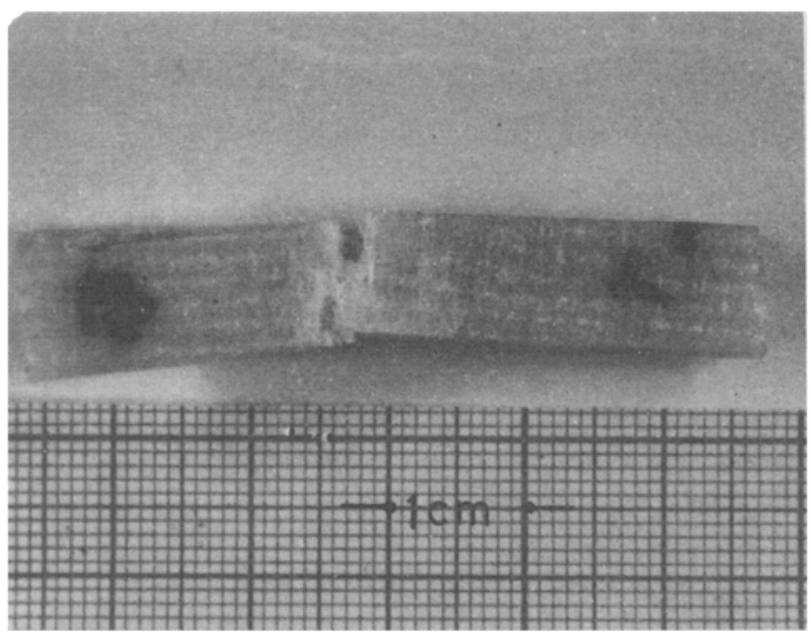

Figure 2. Photograph showing through fracturc in another plain laminate.

often seen transverse through crack at 90 to the thickness side or the length direction is visible. A sample exhibiting an unusually enlarged bright region, due to features such as the fibre pullout, breakage etc is shown in figure 5. Another sample showing an inclined fracture is depicted in figure 6 , which also highlights a lift of the resinous region near the top face.

To explain these observations, as transverse impact loading is involved, the first impacts cause the flaws to originate close to the point of contact. These flaws spread in an outwardly manner causing matrix cracking, fibre breakage and delamination. When fibre breakage and matrix cracks dominate, the crack front emanating from the origin has least distance to traverse to reach the other (non impacting) side along the width, and hence the through fracture results. But this progress may be aided or altered by 


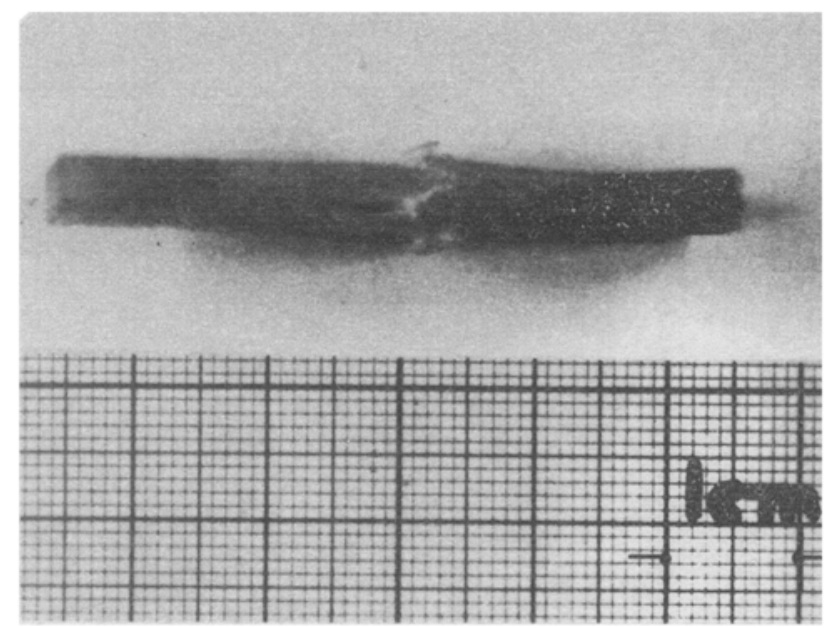

Figure 3. The varied features seen in the sample subjected to tup impacts.

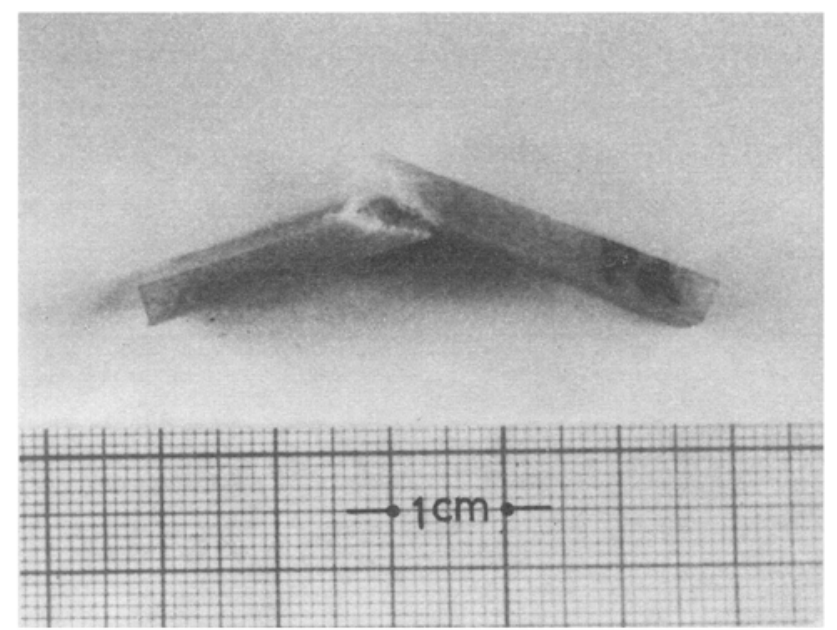

Figure 4. A through width fracture having an inclined path for crack propagation in the case of plain glass-epoxy sample.

local situations like soundness of the laminate, adhesive properties of the resin and fibre etc.

Coming to the foam bearing laminates, the samples containing a greater number of layers of relatively smaller cell size, the impact tests show a through fracture occurring but at an inclination to the thickness of the laminate (figures 7 and 8 ). The separation of the glass-epoxy part from the foam regions, seen faintly in figure 7, is clearly demonstrated in the next sample shown in figure 8. In this latter picture the foam firmly adheres to one side of the sample while the other part containing no foam looks thinner. Some foam bridging the two separated pieces near the centre can also be faintly seen in figure 8 . That the crack although occurring at an inclined angle cannot tear through the foam and thus fully separate the two pieces in a sample is brought about clearly in 


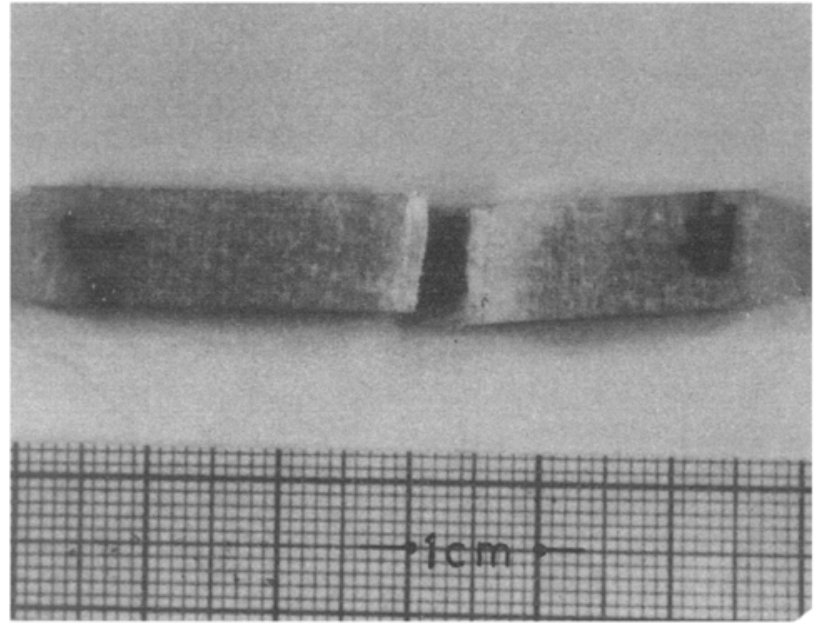

Figure 5. The width face of a sample showing a bright zone on either side of the edge of the fracture.

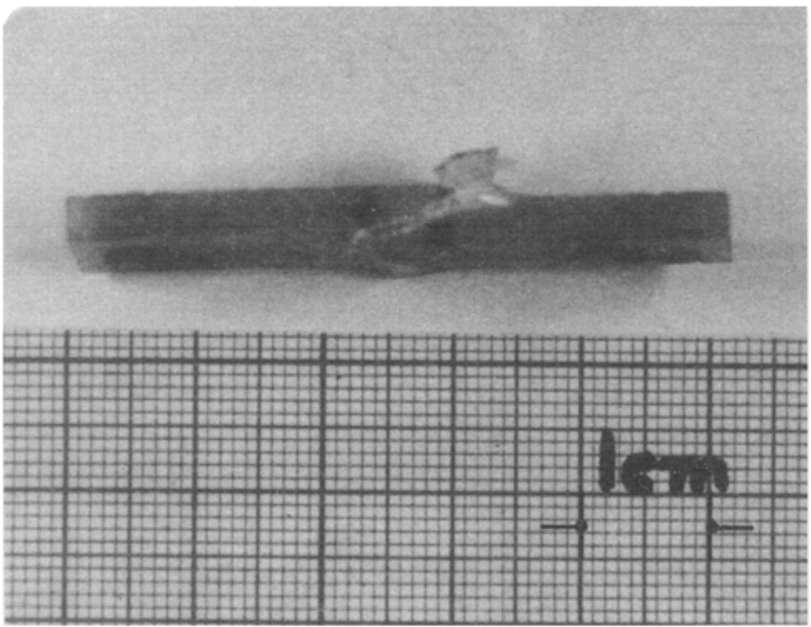

Figure 6. Inclined fracture feature exhibited by a sample.

figure 9 where the left top portion of the test coupon, due to impact, butts into the right side having enough delamination to accommodate the intruding thickness and thus making an appearance resembling the alphabet ' $T$ '. Interestingly, following the bright zone immediately adjoining the split edge corresponding primarily to fibre breakage, there is a dull grey zone on the top side (figure 9) whose total area is much more than the area seen in figure 1 for plain laminates.

The laminate simultaneously preferring an interface separation at the foam/glassepoxy region along with through width fracture is very clearly brought about in figure 10. The crack front needs to travel lesser distance along the width to reach the farther side. This condition should assist in through width fracture. On the other hand 


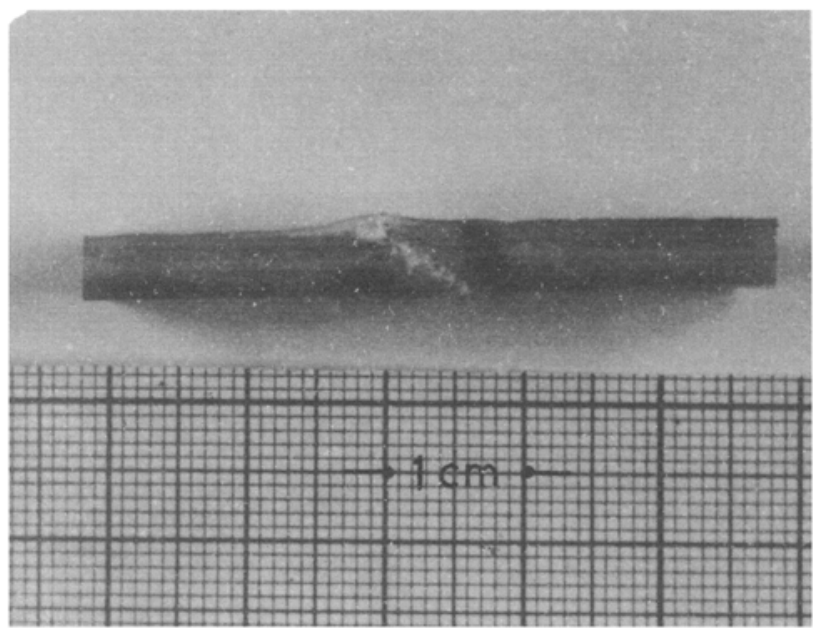

Figure 7. Foam bearing laminates showing an inclined fracture.

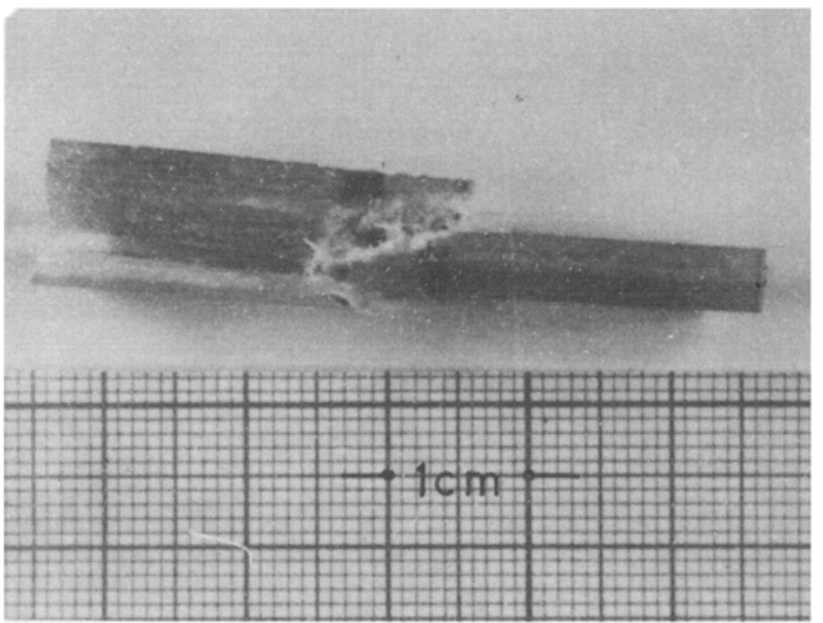

Figure 8. Another illustration of features accompanying a fracture inclined to the thickness in the foam containing sample.

the foam to glass-epoxy interface being weaker, the crack could find this interfacial path an easier one to progress and result in foam/glass-epoxy interface region delaminations. A situation of this nature could be one of the factors for the grey area being well spread in these samples compared to foam free laminates. The macrographs with two layers of a somewhat larger cell size also show features such as through width cracks (figure 11) and irregular fracture features (figures 12 and 13). Like in the other foam samples separation at the foam $/ \mathrm{G}-\mathrm{E}$ interface coupled with a zig zag fracture feature occurs in this case also as depicted in figure 14 .

From the foregoing illustrations it is clear that generally a through width crack at $90^{\circ}$ to the length of the sample is seen with plain laminates while the mid plane separation is 


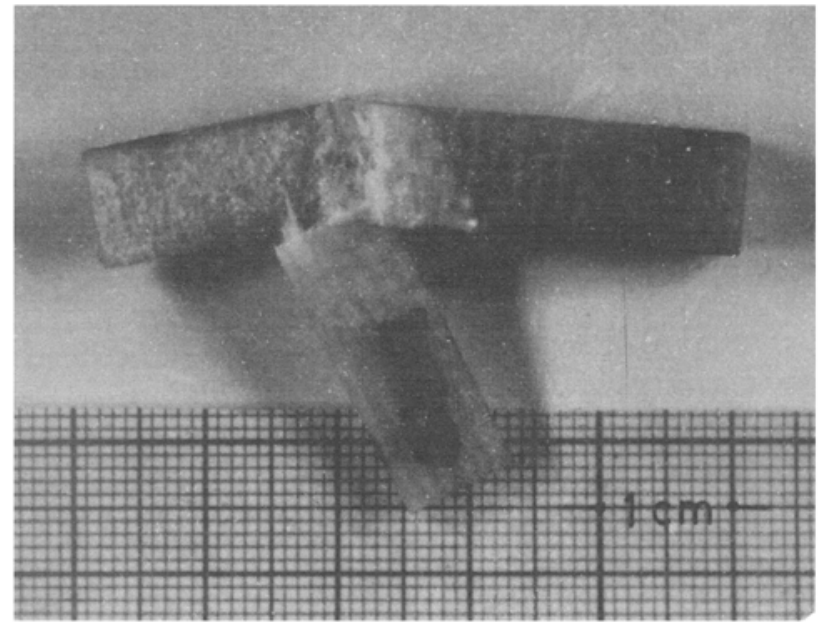

Figure 9. Macrofractograph of a sample showing the swing of one half of the test coupon in relation to the other with the foam acting as a bridge.

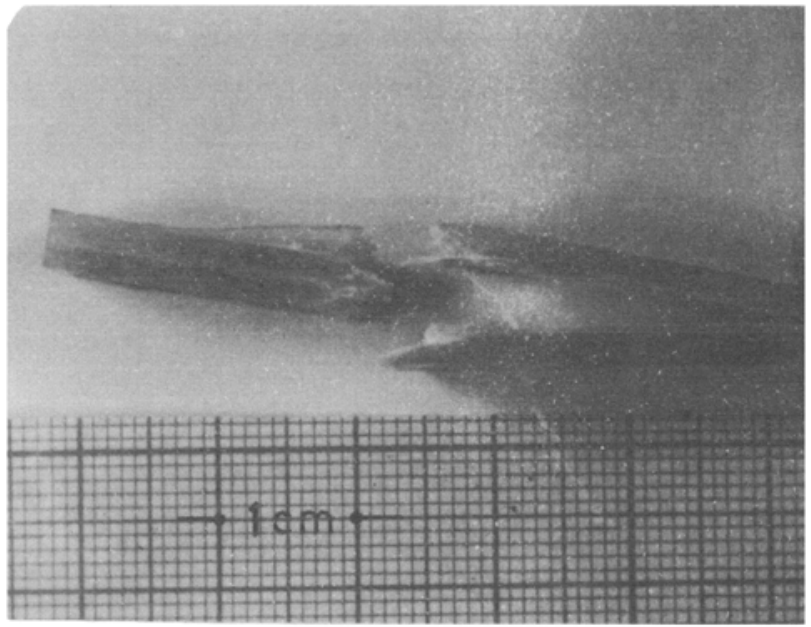

Figure 10. Photograph showing delamination and through width fracture in a foam bearing laminate.

less frequently seen. The inclined fracture is seen in some cases where the angle of inclination is about $45^{\circ}$. The foam bearing ones show a tendency to support crack propagation along the width and also at the region constituting the foam/glass-epoxy system. Also these samples show a tendency for one of the separated zones to cling on to the rest of the sample through the flexible foam. This results in a kind of movement whereby a rotation of one of the fragmented part of the sample, with respect to the rest of the sample due to tup impacts is possible, leading to an appearance of letter ' $T$ '. That the foam separation occurs only on one face of the foam and the glass epoxy region and does not occur on two sides having a similar chemistry simultaneously highlights that 


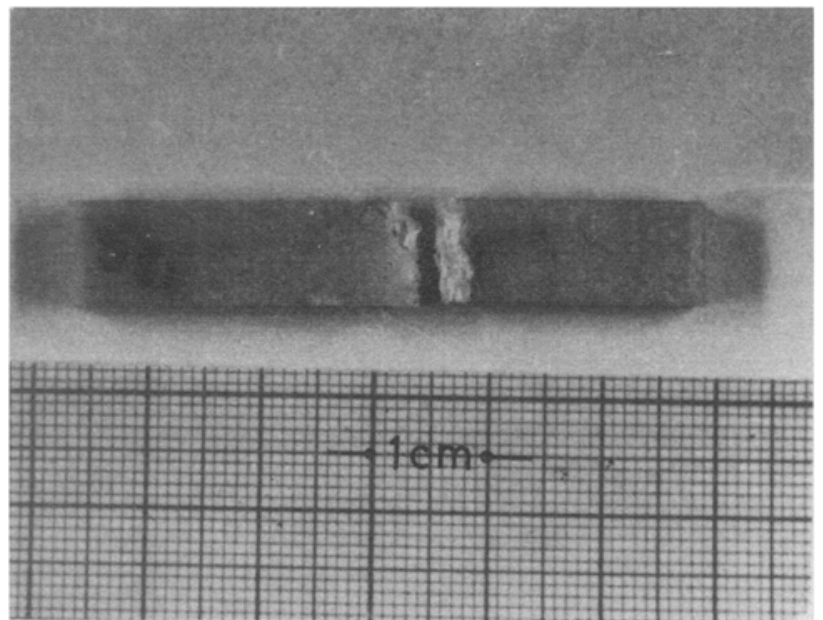

Figure 11. Through width fracture seen in another larger cell sized foam laminate.

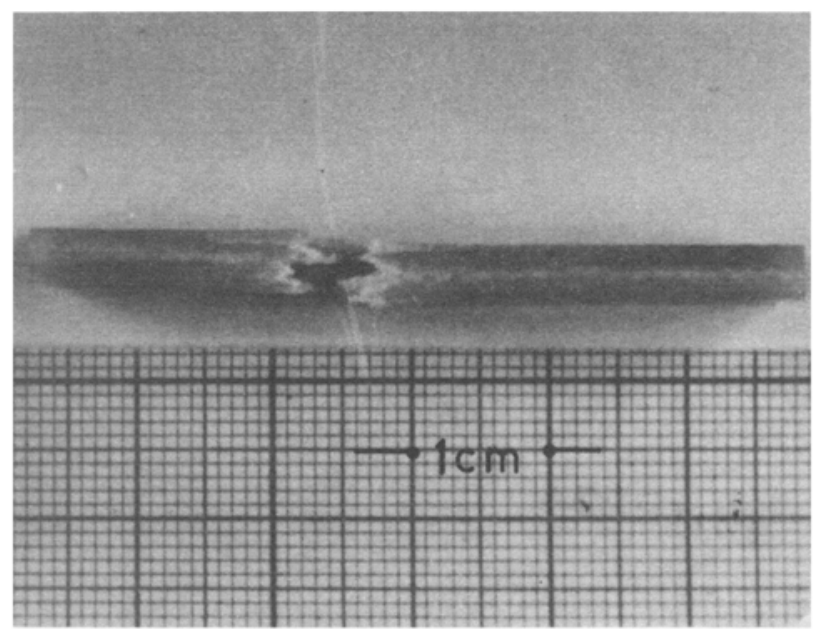

Figure 12. The fractograph illustrating an irregular path of fracture.

between the two interfaces the crack prefers to spread along the one which is the weaker of the two. This region is considered to be weak and accommodative to crack spread.

To bring out these features explicitly in the case of foam bearing samples a coloured liquid penetrant material was used in one of the samples to demarcate the delaminated from the sound areas (figure 15). Also seen in the colour photograph are the features of the compressive failure seen at two regions and tensile features in the other two with the foam acting as a demarcating layer. The foam being flexible accommodates these features on the inner faces.

In figure 15 , the path taken by the interfacial cracks leading to separation is unambiguously brought out. Of interest in these experiments is, whereas the $45^{\circ}$ crack when occurring in plain laminates progresses through a kind of linear fashion (figure 4), the same 


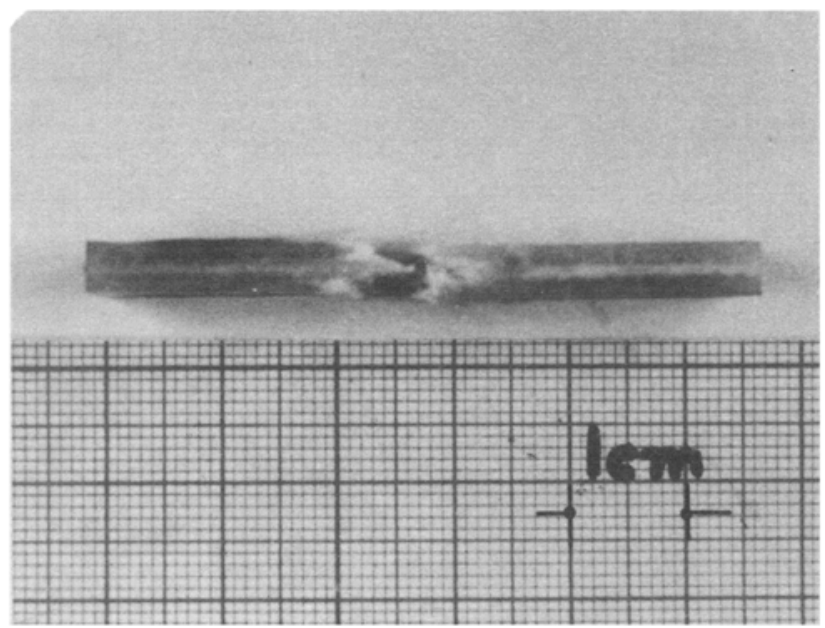

Figure 13. The zig zag appearance seen in a foam laminate.

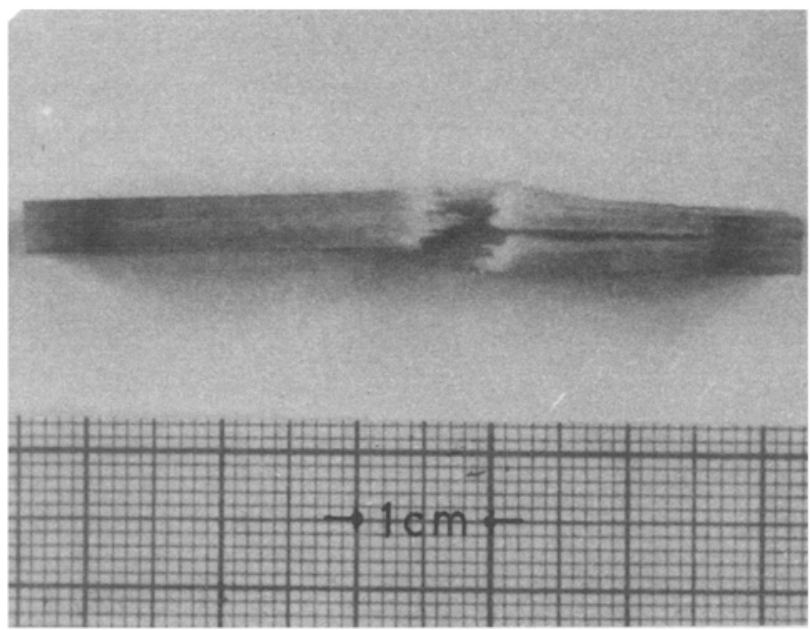

Figure 14. Interface separation accompanied by irregular fracture.

in a foam bearing laminate occurs with a noticeable shift in its path when it encounters the foam region. This particular aspect of the shift is very distinctly brought about in figure 16.

\section{Conclusions}

The macro photography of glass epoxy laminates containing foam shows that through fracture occurs generally in the plain laminates with both the fibre cracking and matrix cracking. A zig zag fracture accompanied by mid plane separation is also seen in some cases. The extent of damage, visible to the unaided eye in the form of a grey colour area, is quite small for the plain laminates. Foam laminates prefer through fracture where a clear separation occurs and when a 45 inclined cracks also accompany, they lead to considerable delamination process at the foam and the glass epoxy regions during the 


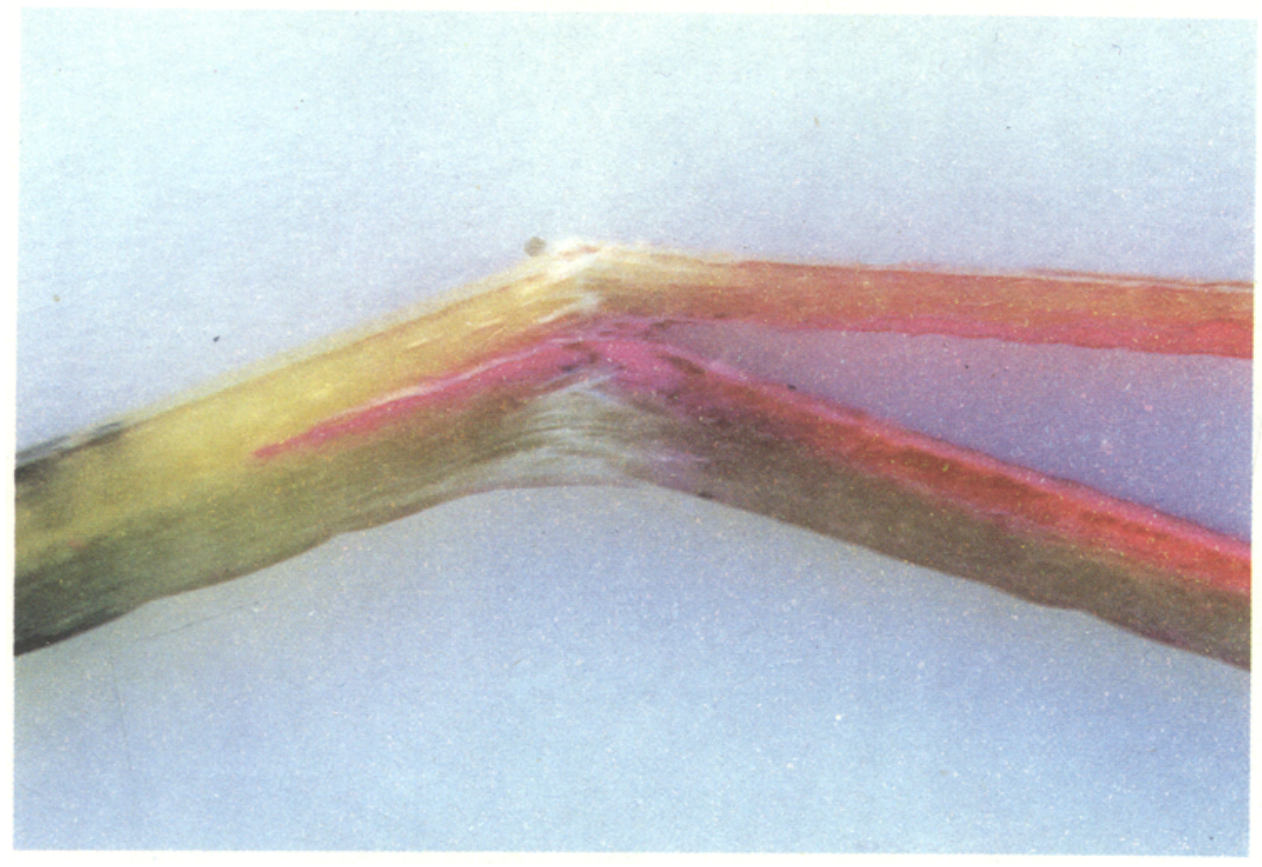

Figure 15. The spread of the dye penetrant distinguishing the interface separation area in the composite.

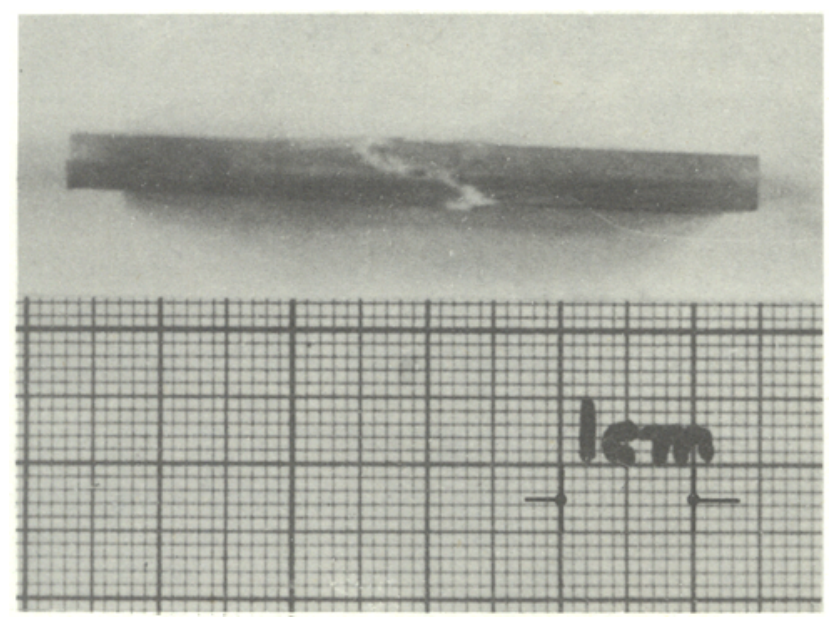

Figure 16. The distinct shift in the path of the crack highlighted in the form of stepped appearance.

period the fracture across the width of the sample can occur. The samples that do not get completely separated shows a tendency of the loosened part to still cling to the other half due to foam acting as a bridging mass. That no foam to foam separation occurs in any of the samples indicates the excellent adhesion and the foam acting as a single entity in these samples. 


\section{Acknowledgements}

The authors thank Prof. D H Sastry, Chairman, Department of Metallurgy, for the facilities extended and the interest shown in this work. The first author (SV) is indebted to Mr Surya Bhattacharya and Mr D Mollaiah for their cooperation and help in the above work. The other author (Kishore) would like to thank the members of his polymer composite group for the useful discussions.

\section{References}

ASM Metals Handbook 1987 vol. 12, ASM International, Metals Park, Ohio 44073, USA

Kaushal S and Kishore 1992 J. Mater. Sci. Lett. 1186

Murthy V S R, Seshan S and Kishore 1987 Microstructural Sciences 15123

Padmanabhan K and Kishore 1990 Bull. Mater. Sci. 13245

Padmanabhan K and Kishore 1994 J. Mater. Sic 2933

Purslow D 1986 Composites 17289

Samajdar S and Kishore 1991 J. Mater. Sci. 26977

Saratchandra D, Rao R M V G K and Kishore 1991 Mater. Sci. \& Enqy. A136 1263

Subramanian C and Kishore 1986 , Ahminitm 62761 